\section{Increase in serum cholesterol during phenytoin treatment}

Long-term treatment with phenytoin is often accompanied by various metabolic and endocrine abnormalities. Particular attention has been paid to effects on pancreatic $\beta$-cells, where it inhibits the release of insulin and suppresses the response of plasma insulin to various stimuli. ${ }^{1}$ Phenytoin also influences thyroid function, reducing serum levels of thyroid hormones and increasing thyroid-stimulating hormone. ${ }^{2}$

Since serum lipid levels are increased in both insulin deficiency and thyroid hypofunction a prospective study of serum lipids, glucose tolerance, and insulin response in patients on phenytoin has been carried out.

\section{Patients, methods, and results}

Eleven formerly untreated patients with epilepsy aged 15-58 years were studied before the institution of phenytoin treatment and $3,6,9$, and 12 months afterwards. Their weights ranged from $89 \%$ to $116 \%$ of normal, and their serum cholesterol and triglyceride levels ranged from 4.7 to $9 \cdot 4$ $\mathrm{mmol} / 1$ (181 to $363 \mathrm{mg} / 100 \mathrm{ml}$ ) and 0.43 to $2.0 \mathrm{mmol} / 1$ (38 to $177 \mathrm{mg}$ $100 \mathrm{ml}$ ), respectively. No patient had clinical or latent diabetes. The dose of phenytoin varied from 300 to $450 \mathrm{mg} /$ day. At each examination body weight, fasting serum cholesterol and triglyceride levels, blood glucose, plasma insulin, and serum levels of phenytoin were measured, and a standard $50-\mathrm{g}$ oral glucose tolerance test was performed.

Two patients were lost from the study after three months. In the nine who completed the 12-month schedule the serum phenytoin levels ranged from 10 to $63 \mu \mathrm{mol} / 1(2.5$ to $15.9 \mu \mathrm{g} / \mathrm{ml})$. The patients maintained stable body weights throughout the study, the greatest individual change being an increase of $2 \mathrm{~kg}$. The serum cholesterol levels increased by 6 to $48 \%$ (mean $19 \% ; \mathrm{P}<0.05$ ) in 9 of the 11 patients during the first three months on phenytoin, the higher level being maintained up to the end of the 12-month period. No consistent change was found in the fasting serum triglyceride levels during treatment (table). Phenytoin caused no significant changes in oral glucose tolerance but there was a clear trend of a diminishing response of plasma insulin to oral glucose during phenytoin administration (table).

Serum Cholesterol and Triglyceride Levels, Oral Glucose Tolerance, and Plasma IRI* Response to Oral Glucose in Nine Epileptic Patients before and during Treatment with Phenytoin. Figures are Means \pm S.E. of Means

\begin{tabular}{|c|c|c|c|c|}
\hline & \multirow{2}{*}{$\begin{array}{c}\text { Before } \\
\text { Phenytoin }\end{array}$} & \multicolumn{3}{|c|}{ After being on phenytoin for: } \\
\hline & & 3 Months & 6 Months & $\begin{array}{c}9-12 \\
\text { Months }\end{array}$ \\
\hline $\begin{array}{l}\text { Serum cholesterol }(\mathrm{mmol} / \mathrm{l}) \\
\text { Serum triglyceride }(\mathrm{mmol} / \mathrm{l}) \\
\text { Sum of baseline glucose value } \\
\text { plus values } \frac{1}{2} \text { an hour and } 1,2, \\
\text { and } 3 \text { hours after oral glucose } \\
\text { loading (mmol/l) } \\
\text { Sum of IRI values } \ldots \\
\text { and } 1,2 \text { and } 3 \text { hours after oral } \\
\text { glucose loading (mU } / \mathrm{l})\end{array}$ & $\begin{array}{r}5 \cdot 5 \pm 0 \cdot 6 \\
0 \cdot 93 \pm 0 \cdot 2 \\
\\
2.3 \cdot 5 \pm 1 \cdot 2 \\
163 \pm 50\end{array}$ & $\begin{array}{r}6.5 \pm 0.8 \\
1.01 \pm 0.2 \\
22 \cdot 2 \pm 1.5 \\
107 \pm 13\end{array}$ & $\begin{array}{r}6 \cdot 4 \pm 0 \cdot 7 \\
1 \cdot 33 \pm 0 \cdot 3 \\
23 \cdot 2 \pm 0 \cdot 8 \\
118 \pm 22\end{array}$ & $\begin{array}{r}6 \cdot 8 \pm 0 \cdot 9 \\
0 \cdot 95 \pm 0 \cdot 2 \\
23 \cdot 2 \pm 1 \cdot 2 \\
97 \pm 12\end{array}$ \\
\hline
\end{tabular}

*IRI = Immunoreactive insulin.

Conversion: SI to Traditional Units

Cholesterol: $1 \mathrm{mmol} / \mathrm{l} \approx 38.5 \mathrm{mg} / 100 \mathrm{ml}$.

Triglyceride: $1 \mathrm{mmol} / 1 \approx 88.5 \mathrm{mg} / 100 \mathrm{ml}$

Glucose: $1 \mathrm{mmol} / 1 \approx 18.0 \mathrm{mg} / 100 \mathrm{ml}$

\section{Discussion}

The mechanism by which phenytoin increases the serum cholesterol level is obscure but the known pharmacological effects of the drug offer at least two possible explanations. Phenytoin decreases the level of circulating thyroid hormones including free thyroxine and triiodothyronine, ${ }^{2}$ and the increase in serum cholesterol could be due to subclinical hypothyroidism. Another explanation is based on the phenobarbitone-like effect of phenytoin on hepatic microsomal enzymes. Phenobarbitone stimulates the hepatic synthesis of cholesterol ${ }^{3}$ and increases the formation and pool size of bile acids, ${ }^{4}$ which in turn may increase the intestinal absorption of cholesterol by facilitating micelle formation.

An increase in serum cholesterol may be regarded as an untoward effect of long-term phenytoin treatment because it increases the risk of coronary heart disease. We therefore suggest that serum cholesterol should be regularly checked in patients undergoing such treatment.

The lack of deterioration in glucose tolerance may have been due to the relatively small doses of phenytoin used. The mean plasma insulin response to oral glucose also remained unchanged during treatment, though a clear tendency of a diminishing insulin secretion occurred, particularly in patients with high pretreatment levels. This observation agreed with the experience of Stambaugh and Tucker.

This study was aided by project grant 01190714 from the Finnish Medical Research Council (Academy of Finland). We thank Mrs. SirkkaLiisa Runeberg for technical help.

1 Kizer, J. S., et al., fournal of Clinical Investigation, 1970, 49, 1942.

2 Molholm Hansen, J., et al., fournal of Clinical Endocrinology and Metabolism, 1974, 39, 785.

3 Jones, A. L., and Armstrong, D. T., Proceedings of the Society for Experimental Biology and Medicine, 1965, 119, 1136.

4 Redinger, R. N., and Small, D. M., fournal of Clinical Investigation, 1973, 52,161 .

5 Stambaugh, J. E., and Tucker, D. C., Diabetes, 1974, 23, 679.

Third Department of Medicine and Department of Neurology,

University of Helsinki, 00290 Helsinki 29, Finland

RISTO PELKONEN, M.D., Consultant in Endocrinology

RAINER FOGELHOLM, M.D, Associate Physician in Chief

ESKO A. NIKKIL ̈̈, M.D., Professor of Medicine

\section{Enteric-coated aspirin overdose and gastric perforation}

Enteric-cozted aspirin is claimed not to irritate gastric mucosa. We report a case of fatal gastric perforation due to Safapryn. Safapryn consists of a sugar-coated tablet containing $250 \mathrm{mg}$ of paracetamol outside an enteric-coated core of $300 \mathrm{mg}$ of aspirin. The enteric coat is cellulose acetate phthallate, which disintegrates when the $\mathrm{pH}$ rises to $6 \cdot 8$.

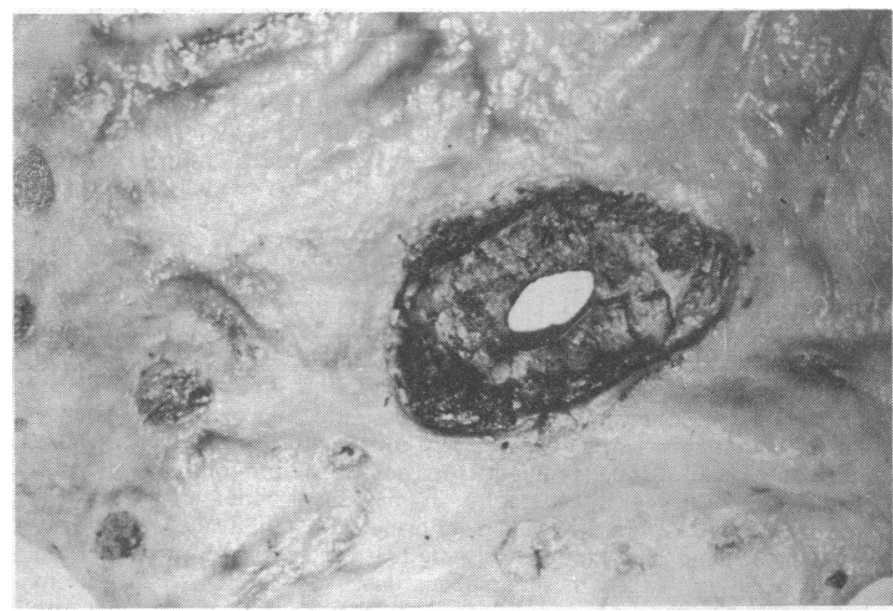

Mucosa of greater curvature of stomach showing perforation and erosions at sites of contact with enteric-coated aspirin cores. 


\section{Case Report}

An 83-year-old woman was admitted to hospital with a fracture of the neck of the right femur. Before admission she was being treated for arthritis with the following: Safapryn six tablets, phenylbutazone $300 \mathrm{mg}$, ampicillin $1 \mathrm{~g}$ and ethylestrenol $2 \mathrm{mg}$ daily and nitrazepam $5 \mathrm{mg}$ nightly. These drugs were continued throughout her stay in hospital. An Austin-Moore prostheșis was inserted at operation on the right hip. She was recovering satisfactorily until her general condition unexpectedly deteriorated 22 days after admission and she died 24 hours later.

Necropsy showed peritonitis arising from three acute perforations of the stomach. The largest, $1 \mathrm{~cm}$ in diameter, was in the greater curvature. The others were in the anterior and posterior walls of the pylorus. There was no pyloric stenosis. The stomach and intestines contained altered blood. There were 67 tablets in the stomach. The mucosa of the greater curvature around the perforation showed multiple erosions, apparently where tablets were in contact with the mucosa (see fig.). The heart, lungs, and liver appeared normal. The tablets were all enteric-coated aspirin identical to the inner core of Safapryn. Free aspirin was not found in a sample of stomach contents. Post-mortem blood contained $1.03 \mathrm{mmol} / 1(156 \mu \mathrm{g} / \mathrm{ml})$ of paracetamol, and $363 \mu \mathrm{mol} / 1(50 \mu \mathrm{g} / \mathrm{ml})$ of salicylate. No other drugs were detected in the blood or stomach contents.

\section{Discussion}

An overdose of Safapryn tablets was taken, from which paracetamol was absorbed but little aspirin was released Nevertheless, the local concentration of mucosal irritants at sites in contact with tablets seems to be important, ${ }^{1}$ and the gastric erosions suggest that local release of aspirin from some tablets may have caused the ulceration. We should be aware that enteric-coated aspirin does not ensure safety from gastric toxicity.

We thank Dr. L. F. Prescott for advice.

${ }^{1}$ Heffernan, S. J., and Murphy, J. J., British Medical Yournal, 1975, 2, 746.

Hope Hospital, Salford, Manchester M6 8HD

R. J. FARRAND, M.R.C.PATH., Consultant Pathologist

J. H. GREEN, F.R.C.S.ED., Consultant Orthopaedic Surgeon

C. HAWORTH, PH.D., Biochemist

\section{Arthroscintigraphy with technetium albumin in diagnosis of pseudophlebitis (Baker's) cyst}

The differential diagnosis of an acute or subacute tender swelling in the calf or popliteal fossa includes thrombophlebitis, dissecting popliteal (Baker's) cyst, gastrocnemius tear, benign neoplasms, and aneurysm. The most difficult and most common differential diagnosis is between thrombophlebitis and dissecting popliteal cyst. We evaluated a simple benign procedure-arthroscintigraphy, using an intra-articular injection of high specific activity ${ }^{9} \mathrm{~m}$ Tc labelled human serum albumin (H.S.A.)- to confirm or refute the diagnosis.

\section{Patients, methods, and results}

Sixteen patients were studied. Under aseptic conditions $3-5 \mathrm{mCi}$ of $99 \mathrm{mTc}$ H.S.A. in $1-1.5 \mathrm{ml}$ was injected intra-articularly into the affected knee joint. At three and 24 hours the leg was imaged from six inches above the injection site to the ankle, using a five-inch $(13 \mathrm{~cm})$ crystal rectilinear scanner.

The arthroscintigram showed dissection or rupture of a cyst in six patients. Eight of the patients had venography and four were shown to have venous thrombosis; in all of these four patients the arthroscintigram was normal. Five patients underwent arthrography. In one patient with a normal arthrogram the arthroscintigram showed an abnormal large popliteal cyst (see fig.). The six patients with positive scans included three with symptoms related to athletic activity, two with spontaneous onset of symptoms, and one in whom symptoms were associated with prior rheumatoid arthritis. Because of the strong clinical suspicion of acute thrombophlebitis seven of these patients had been started on heparin one to six days before the scanning procedure.

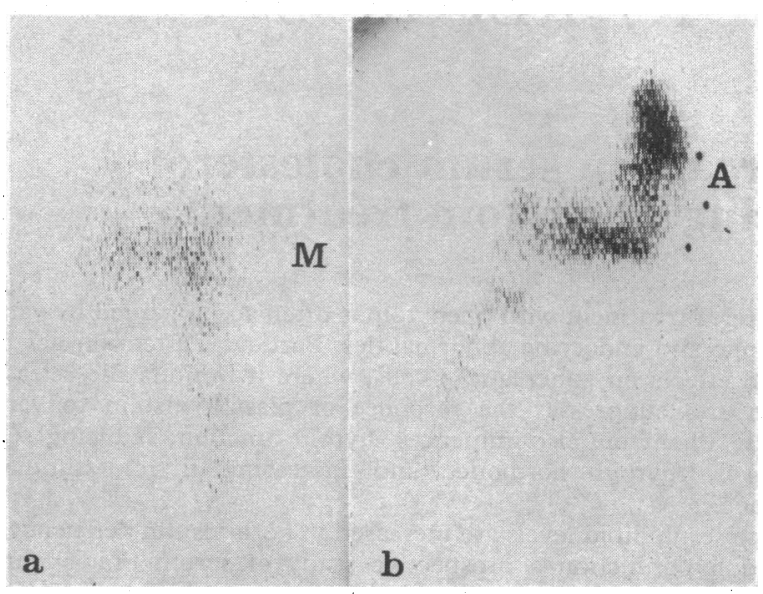

Arthroscintigrams of left knee showing entrance of tracer posteriorly into popliteal cyst and extending downwards to middle of calf region; this was diagnostic of dissection or rupture of Baker's cyst. (a) Posterior view. (b) Lateral view. A. = Anterior. M. = Medial.

\section{Discussion}

In 1877 Baker $^{1}$ described the cyst that bears his name. About $40 \%$ of normal knees have a valvular opening in the posterior capsule resulting in a communication between the knee joint and the normal bursa situated anterior to the medial head of the gastrocnemius muscle. $^{2}$ This communication is generally narrow and the valve mechanism allows free passage of fluid from the knee joint to the popliteal bursa, but not in the reverse direction.

Though specific, arthrography using gas or opaque contrast media is not without risk. Complications, such as contrast-media hypersensitivity or pain due to subcutaneous infiltration or synovial rupture caused by over-distention of the joint space, occur during a small percentage of examinations. In contrast, arthroscintigraphy using a labelled radiodiagnostic material maintains a high degree of specificity without loss of sensitivity but does not result in these hazards.

The clinical similarity of thrombophlebitis and a dissecting inflamed popliteal cyst is so great that the dissecting cyst has been dubbed as pseudophlebitis. Since the implications of having thrombophlebitis are so grave, however, it is essential to establish the diagnosis definitely; thus unnecessary exposure to anticoagulants of patients with pseudophlebitis may be prevented. The diagnosis of a dissecting popliteal cyst should be considered in a patient with an apparent positive Homan's sign and associated swelling of the popliteal fossa with swelling of the calf, particularly if the calf swelling is predominantly medial and no palpable firm vein ("cord") is present.

Recently, several reports have described the clinical usefulness of radionuclide arthrography after the intra-articular injection of ${ }^{131} \mathrm{I}$ H.S.A. ${ }^{34}$ But the preferable physical characteristics of $99 \mathrm{~m} T \mathrm{Tc}$ (140-keV photon emission, six-hour physical half life, and decreased adsorbed radiation dose) make this nuclide a much more desirable radiolabel. Because of these features, millicurie rather than microcurie quantities can be used and, thus, much better resolution images are obtained.

We thank Dr. Werner Barth for his continued and enthusiastic support.

${ }^{1}$ Baker, W. M., St. Bartholomew's Hospital Reports, 1877, 13, 245.

2 Taylor, A. R., and Rana, N. A., Annals of the Rheumatic Diseases, 1973, 32, 419.

${ }^{3}$ Pozderas, R. V., and Good, A. E., fournal of Nuclear Medicine, 1974, 15, 7.

4 Schmidt, M. C., Workman, J. B., and Barth, W. F., Archives of Internal Medicine, 1974, 134, 694.

Department of Radiology (George Washington University) and Department of Nuclear Medicine, Washington Hospital Center, Washington D.C., U.S.A.

A. E. WATKINS, M.D., Fellow

K. P. POULOSE, M.D., Associate Professor

R. C. REBA, M.D., Professor 